\title{
Discovery of a natural small-molecule compound that suppresses tumor EMT, stemness and metastasis by inhibiting TGF $\beta / B M P$ signaling in triple-negative breast cancer
}

Lei $\mathrm{Di}^{1+}$, Li-Juan Liu ${ }^{1+}$, Yong-Ming Yan ${ }^{2+}$, Rong Fu', Yi Li ${ }^{1}$, Ying Xu', Yong-Xian Cheng ${ }^{2 *}$ and Zhao-Qiu Wu ${ }^{1 *}$

\begin{abstract}
Background: The transforming growth factor $\beta$ (TGF $\beta$ ) and bone morphogenetic protein (BMP) signaling pathways are both constitutively activated in triple-negative breast cancer (TNBC). We are interested in isolating the naturallyderived small-molecule inhibitor that could simultaneously targeting TGF $\beta / B M P$ pathways and further studying its anti-proliferative/-metastatic effects as well as the underlying mechanisms in multiple tumor models.

Methods: Multiple in vitro cell-based assays are used to examine the compound's inhibitory efficacy on TNBC cell growth, stemness, epithelial-mesenchymal transition (EMT), invasion and migration by targeting TGF $\beta / B M P$ signaling pathways. Transgenic breast cancer mouse model (MMTV-PyMT), subcutaneous xenograft and bone metastasis models are used to examine ZL170's effects on TNBC growth and metastasis potentials in vivo.

Results: ZL170 dose-dependently inhibits cell proliferation, EMT, stemness, invasion and migration in vitro via specifically targeting canonical TGFB/BMP-SMADs pathways in TNBC cells. The compound significantly hinders osteolytic bone metastasis and xenograft tumor growth without inflicting toxicity on vital organs of tumor-bearing nude mice. ZL170 strongly inhibits primary tumor growth and lung metastases in MMTV-PYMT transgenic mice. ZL170-treated tumors exhibit impaired TGF $\beta / B M P$ signaling pathways in both epithelial and stromal compartments, thereby creating a suppressive tumor microenvironment characterized by reduced extracellular matrix deposition and decreased infiltration of stromal cells.
\end{abstract}

Conclusions: ZL170 inhibits tumor EMT, stemness and metastasis and could be further developed as a potent antimetastatic agent used in combination with cytotoxic drugs for treatment of TNBC and other advanced metastatic cancers.

Keywords: ZL170, Triple-negative breast cancer, Epithelial-mesenchymal transition, TGFß/BMP, Metastasis

\footnotetext{
* Correspondence: yxcheng@szu.edu.cn; zqwu@cpu.edu.cn

'Lei Di, Li-Juan Liu and Yong-Ming Yan contributed equally to this work. ${ }^{2}$ Guangdong Key Laboratory for Genome Stability \& Disease Prevention, School of Pharmaceutical Sciences, Shenzhen University Health Science Center, 3688 Nanhai Ave, Shenzhen 518060, China

'State Key Laboratory of Natural Medicines, Jiangsu Key Laboratory of Carcinogenesis and Intervention, School of Basic Medicine and Clinical Pharmacy, China Pharmaceutical University, Nanjing 211198, China; Collaborative Innovation Center for Gannan Oil-Tea Camellia Industrial Development, Gannan Medical University, Ganzhou, China
}

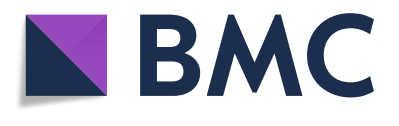

(c) The Author(s). 2019 Open Access This article is distributed under the terms of the Creative Commons Attribution 4.0 International License (http://creativecommons.org/licenses/by/4.0/), which permits unrestricted use, distribution, and reproduction in any medium, provided you give appropriate credit to the original author(s) and the source, provide a link to the Creative Commons license, and indicate if changes were made. The Creative Commons Public Domain Dedication waiver (http://creativecommons.org/publicdomain/zero/1.0/) applies to the data made available in this article, unless otherwise stated. 


\section{Background}

The transforming growth factor $\beta$ (TGF $\beta$ ) superfamily of cytokines, which comprises three TGF $\beta$ isoforms (TGF $\beta 1$, TGF $\beta 2$ and TGF $\beta 3$ ), bone morphogenetic proteins (BMPs; BMP1 BMP7), nodals, activins, inhibins and others, is evolutionarily conserved and actively involved in many cellular processes including cell proliferation, migration, invasion, epithelial-mesenchymal transition (EMT), extracellular matrix (ECM) remodeling, angiogenesis and immune suppression [1-4]. TGF $\beta$ and BMPs transduce their signals through two highly conserved single transmembrane serine/threonine kinase receptors, termed type II receptors (TGFBR2 for TGF $\beta$ and BMPR2 for BMPs) and type I receptors (TGFBR1 (i.e. ALK5) for TGF $\beta$ and BMPR1A/1B (i.e. ALK3/6) for BMPs). Upon ligand binding and resultant heterotetrameric receptor complex formation, the activated type II receptors phosphorylate (activate) type I receptors [1-5]. Activated TGFBR1 in turn phosphorylates both Smad2/3 and Smad1/5 (but prefers to target Smad2/3), while activated BMPR1A/1B phosphorylate Smad1/5 [1-5]. The phospho-Smad1/5 and phospho-Smad2/3 interact with common mediator Smad (co-Smad), Smad4, translocate to the nucleus and initiate transcriptional activation or transcriptional repression of target genes [1-5]. The TGF $\beta$ and BMP signaling pathways are known to play pleiotropic roles in cancer progression and their action is highly cellular context-dependent $[2,6,7]$. In tumor initiation, TGF $\beta$ and BMPs inhibit cell growth and act as tumor suppressors, while in later stages, they promote cell proliferation, EMT, stemness, invasion and metastasis $[2,6,7]$.

Breast cancer is the most common malignancy and the second leading cause of cancer mortality among women in the worldwide. Among the four molecular subtypes (luminal A, luminal B, Her2-enriched and triple-negative/ basal-like), triple-negative breast cancer (TNBC) displays stronger invasiveness, higher risk of metastasis and poorer prognosis $[8,9]$. The existing endocrine therapy, Her2-targeted therapy and chemotherapy have been proven ineffective for TNBC treatment. TGF $\beta$ and BMP ligands as well as their receptors are chronically overexpressed in TNBC and the elevated ligand/receptor levels in tumor tissues or in patients' plasma correlate with more metastatic phenotypes and shorter patient survivals $[1,10,11]$. Accordingly, blockade of TGF $\beta$ and BMP signaling pathways is an attractive anti-cancer therapeutic approach. A variety of small-molecule TGF $\beta$-specific or BMP-specific inhibitors are currently in the process of development $[1,12,13]$. However, the dual inhibitors that target TGF $\beta$ and BMP kinase receptors have not been characterized and studied yet.

The potential of naturally-derived small molecule compounds as the candidates for drug discovery has been well recognized [14]. The crude extracts of Periplaneta americana have been used as an anti-bacterial, antiviral, anti-inflammatory, anti-tumor, anti-fibrosis, and tissue-repair agent in traditional Chinese medicine for years. We are interested in compounds thereof responsible for anticancer effects which so far remains largely unknown. In the present study, we have isolated a structurally novel small-molecule oxindole compound, ZL170 from the dry whole bodies of $P$. americana, and further identified the compound as a potent dual inhibitor of TGF $\beta$ and BMP kinase receptors. Our results indicate, for the first time, that simultaneous abrogation of TGF $\beta$ and BMP signaling pathways by systemic administration of the naturally derived TGF $\beta /$ BMP dual inhibitor could result in substantially reduced tumor growth, invasion and metastasis in TNBC and other metastatic cancer types. ZL170 could be further developed as a potent anti-metastasis agent used in combination with immune checkpoint inhibitors or cytotoxic drugs for treatment of TNBC and other advanced metastatic cancers.

\section{Materials and methods}

Extraction, total synthesis and characterization of ZL170 For extraction of ZL170, the dry whole bodies of P. americana $(30 \mathrm{~kg})$ were extracted by refluxing with $70 \% \mathrm{EtOH}$ $(3 \times 120 \mathrm{~L} \times 2 \mathrm{~h})$ to give a crude extract, which was suspended in water followed by extraction with EtOAc to afford an EtOAc soluble extract (230 g). Detailed protocols are described in Supplementary information.

\section{Cell culture}

MDA-MB-231, 4 T1 and HEK293T cells were obtained from ATCC, and MDA-MB-231-SCP2 cells were kindly provided by J. Massague (Memorial Sloan-Kettering Cancer Center, New York, USA). The cells were grown in DMEM medium (Thermo Fisher) supplemented with $10 \%$ fetal bovine serum (FBS) and 1\% penicillin/streptomycin (Thermo Fisher). PyMT breast cancer cell line was generated in our laboratory [15] and cultured in DMEM/F12 medium containing 5\% FBS, $10 \mathrm{ng} / \mathrm{ml} \mathrm{EGF,}$ $500 \mathrm{ng} / \mathrm{ml}$ hydrocortisone, $5 \mathrm{mg} / \mathrm{ml}$ insulin, $20 \mathrm{ng} / \mathrm{ml}$ cholera toxin and $1 \%$ penicillin/streptomycin. Cells were tested for mycoplasma contamination every 2 weeks, and only mycoplasma-negative cells were used. All cell lines in this study were authenticated in our laboratory.

\section{Cell transfection}

Cells were transfected using Lipofectamine2000 (Thermo Fisher) according to the manufacturer's instructions. The luciferase activity was determined by the Dual-Luciferase Reporter Assay system kit (Promega) according to the manufacturer's instructions. 
Cloning, virus production and infection

pGL3-SBE4, pGL3-BRE4, pLenti-HA-TGFBR1-T204D, pLenti-HA-BMPR1A-Q233D, pLKO.1-BMPR1A-shRNA and pLKO.1-TGFBR1-shRNA were generated by GenScript Biotech Inc. (Nanjing, China). To produce lentivirus, $293 \mathrm{~T}$ cells were transfected with transfer plasmid, psPAX2 and pMD2.G. Cells were fed with fresh medium $24 \mathrm{~h}$ post transfection, and conditioned medium containing viral particles was harvested $48 \mathrm{~h}$ and $72 \mathrm{~h}$ post transfection. For virus infection, target cells were incubated with a mixture of virus-containing medium and culture medium at a ratio of $1: 1$ for $24 \mathrm{~h}$ in the presence of $8 \mu \mathrm{g} / \mathrm{ml}$ Polybrene (Sigma). Cells were re-infected for another $24 \mathrm{~h}$, recovered in fresh medium for $24 \mathrm{~h}$ and selected in culture medium containing puromycin for 1 week.

\section{Cell migration and invasion assays}

For migration and invasion assays, cells were seeded in upper insert in serum free medium in the absence (for cell migration assay) or presence (for cell invasion assay) of Matrigel pre-coated on the bottom (BD Bioscience). The lower chamber was filled with complete medium. After incubation period, cells were fixed with methanol for $10 \mathrm{~min}$, stained by $0.5 \%$ crystal violet and counted under microscope.

\section{Western blotting and antibodies}

Cells were washed in pre-cold PBS and lysed using radio-immunoprecipitation assay (RIPA) buffer (Thermo Fisher) supplemented with proteinase and phosphatase inhibitors (Thermo Fisher). Cell lysates was subjected Western blotting assays as described in Supplementary information.

\section{RNA preparation and qRT-PCR}

The total RNA was isolated with a TRIzol kit (Invitrogen). Reverse transcription of purified RNA was performed using Prime Script ${ }^{\text {th }}$ RT reagent Kit with gDNA Eraser (TaKaRa). qRT-PCR was performed using qPCR Master Mix (Vazyme). GAPDH mRNA level was recognized as an endogenous control for each target gene. Primer sequences are available upon request.

\section{Flow cytometry analysis}

The percentage of apoptotic cells was determined by the FITC Annexin V Apoptosis Detection Kit I (BD Bioscience) according to the manufacturer's instructions. In some experiments, ALDH activity of MDA-MB-231 cells was measured using a kit from STEMCELL Technologies according to the manufacturer's instructions.

\section{RNA sequencing}

The total RNA was isolated with a TRIzol kit (Invitrogen). Sequencing libraries were generated using NEBNext UltraTM RNA Library Prep Kit for Illumina (NEB) following the manufacturer's recommendations and index codes were added to attribute sequences to each sample.

\section{In vivo tumor growth and bone metastasis assays}

Six-week-old female athymic Balb/c nu/nu mice and MMTV-PyMT transgenic mice were purchased from Qinglongshan Animal Facility (Nanjing, China) and Jackson Laboratory, respectively. All mice were housed under standard specific-pathogen-free (SPF) conditions and all research involving animals strictly complied with protocols approved by the Animal Welfare and Ethics Committee of China Pharmaceutical University.

\section{Histological, immunofluorescent and immunohistochemical analyses}

Femurs and tibias were excised, fixed in 10\% neutral-buffered formalin, decalcified and embedded in paraffin. Non-skeletal organs were dissected, fixed in $3.7 \%$ formaldehyde and embedded in paraffin. Tissues were sectioned and stained. Detailed protocols are described in supplementary information.

\section{Micro-computed tomography $(\mu \mathrm{CT})$ assay}

Femurs and tibias were scanned using the Hiscan M1001 $\mu \mathrm{CT}$ (Hiscan Information Technology Inc., China). The $\mathrm{X}$-Ray tube settings were $60 \mathrm{kV}$ and $133 \mu \mathrm{A}$ and images were acquired at $50 \mu \mathrm{m}$ resolution. A $0.5^{\circ}$ rotation step through a $360^{\circ}$ angular range with $50 \mathrm{~ms}$ exposure per step was used. The images were reconstructed with Hiscan Reconstruct software (Hiscan Information Technology Inc., China) and analyzed with Hiscan Analyzer software (Hiscan Information Technology Inc., China). After processing with a 3-D Gaussian filter to reduce noise.

\section{Molecular docking}

The crystal structures for docking were downloaded from Protein Data Bank (PDB). All the simulations were applied through Schrödinger. Preparation of the crystal structures of TGF $\beta / B M P$ receptors were carried out using the Protein Preparation Wizard module. Proper preparation of the ligands was accomplished by the LigPrep module. All other parameters were set to the default values. The cavity that surrounded within $10 \AA$ of the ligand in each complex was defined as the binding site. Compounds ZL170 was docked into the binding pockets of TGF $\beta / B M P$ receptors by Glide_SP module. Then the visualization was performed by the program Pymol. 


\section{Statistics analysis}

Data were presented as mean \pm SD. Statistical analysis was performed as described in each figure legend, and sample sizes were shown in each corresponding figure legend. $P<0.05$ is considered as significant.

\section{Results}

The chemical structure, total synthesis and acute toxicity of ZL170

ZL170 extracted from the dry whole bodies of P. americana is a HPLC-grade pure small-molecule oxindole compound, (E)-3-(3,4-dihydroxybenzylidene)-5-hydroxyindolin-2-one $\left(\mathrm{C}_{15} \mathrm{H}_{11} \mathrm{NO}_{4} ; \mathrm{MW}, 269\right)$ (Fig. 1a; Additional file 1: Figure S1A). Total synthesis of ZL170 is shown in Additional file 1: Figure S1B. The detailed characterization and purity of the naturally extracted and total synthetic ZL170 are presented in Additional file 1: Figure S1C and D. Acute toxicity studies revealed that C57BL6 mice intraperitoneally (i.p.) injected with a single dose of ZL170 up to $600 \mathrm{mg} / \mathrm{kg}$ experienced no obvious adverse health effects during a 7-day observation (Additional file 1: Figure S2A).
ZL170 specifically targets the TGF $\beta$ and BMP signaling pathways in TNBC cells

We first sought to determine whether ZL170 could affect cell migration and invasion in a variety of basal, TNBC cell lines. As shown in Fig. 2a-i, without affecting cell viability, ZL170 dose-dependently inhibited cell migration and invasion in vitro in two well-established TNBC cell lines (MDA-MB-231 and 4 T1) as well as in a primary cell line derived from late-stage MMTV-PyMT breast tumors (TNBC-like cells; [15]). After $48 \mathrm{~h}$ treatment, ZL170 inhibited cell proliferation in a dosedependent manner (by $\sim 35 \%$ at $20 \mu \mathrm{M}$ ) but did not induce obvious apoptosis in the TNBC cell lines (Fig. $2 \mathrm{j}$ and $\mathrm{k}$ ). To assess the global impact of ZL170 on TNBC cell function in an unbiased fashion, mRNA was isolated from vehicle- and ZL170-treated MDA-MB-231 cells and subjected to RNA sequencing. Using a minimum of two-fold change as a cutoff, ZL170 altered the expression of 434 unique transcripts (95 transcripts increased and 339 transcripts decreased; Fig. 1b and c). Gene set enrichment analysis (GSEA) further revealed that ZL170 modulated the expression of signature genes involved in

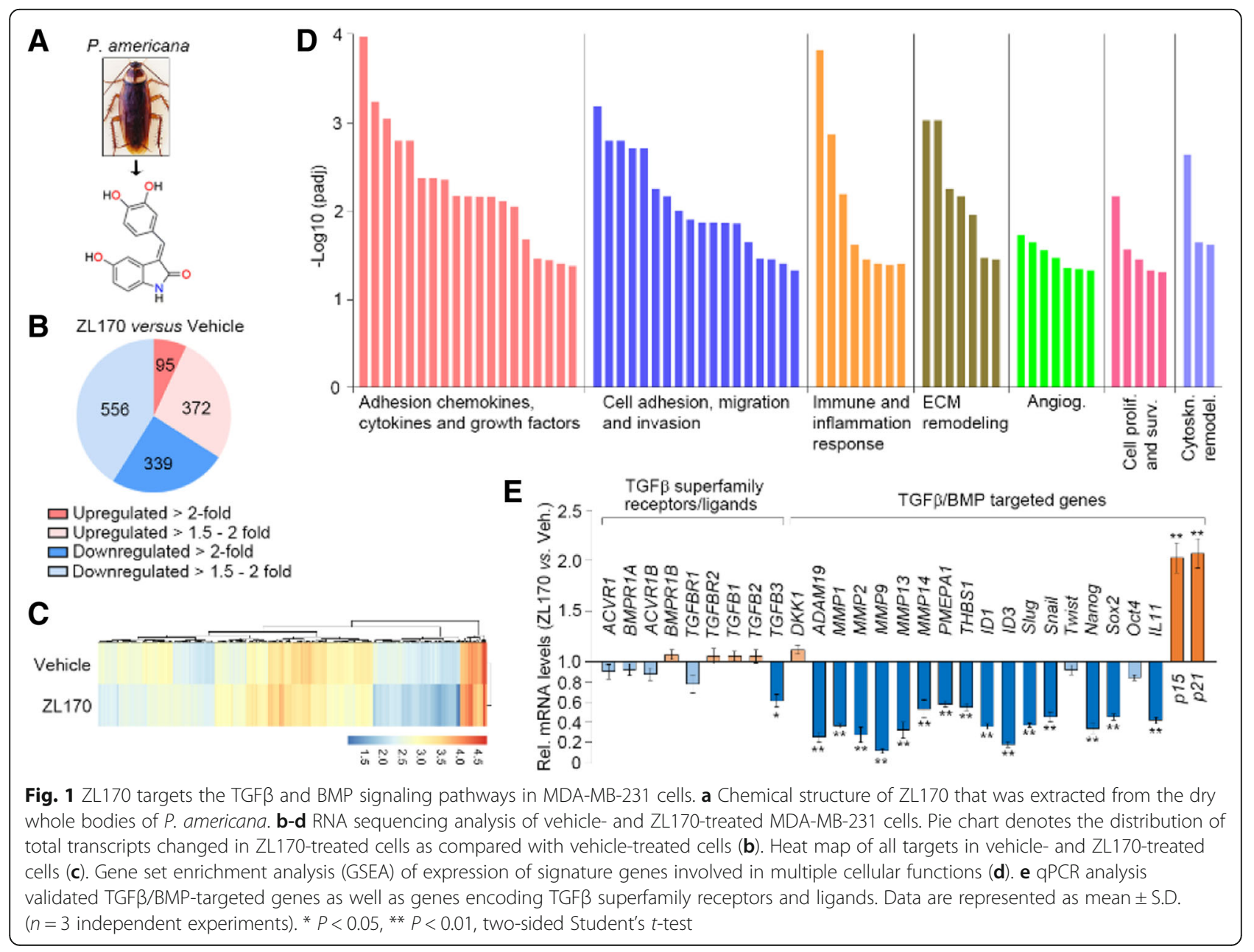




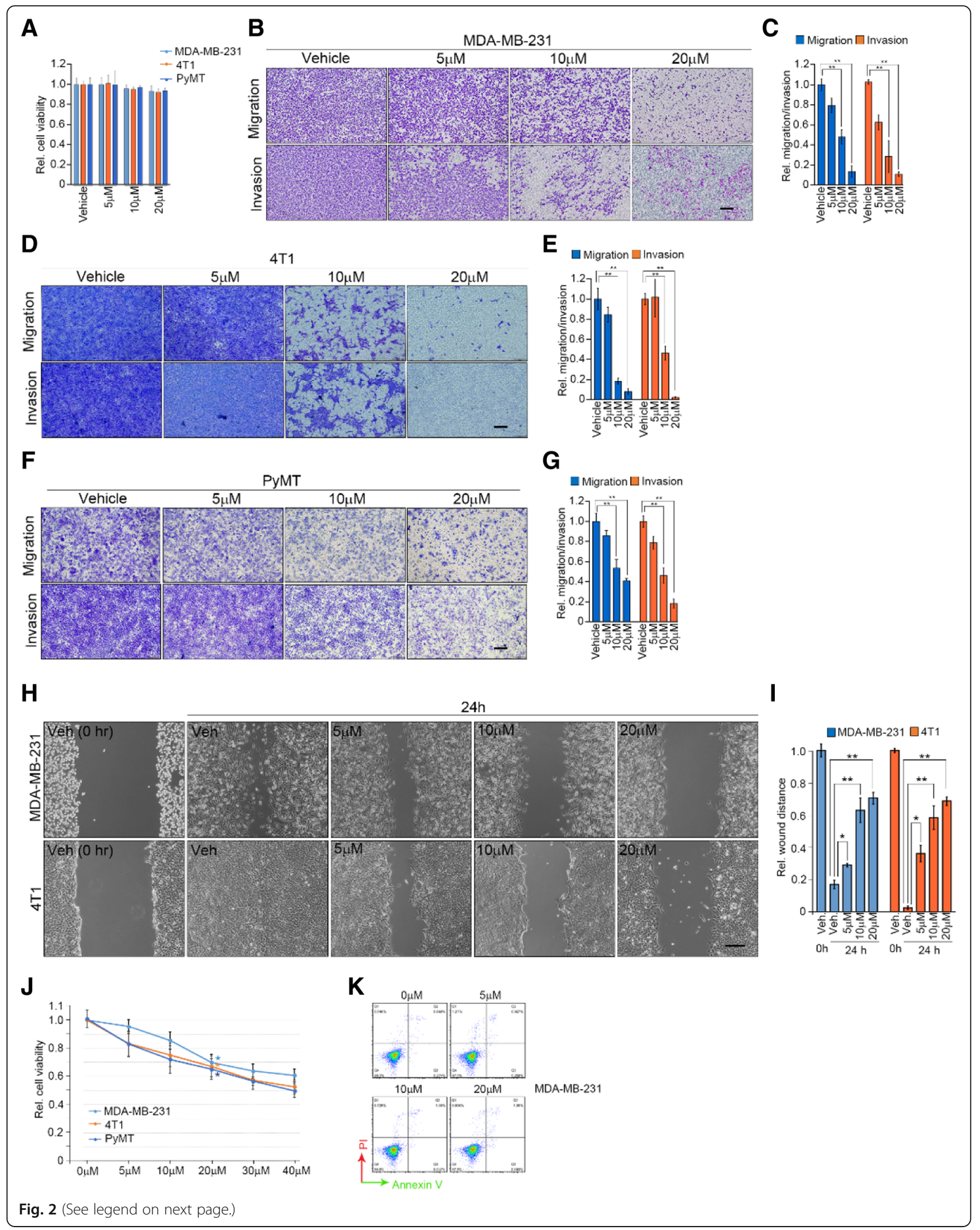


(See figure on previous page.)

Fig. 2 ZL170 reduces TNBC cell migration, invasion and proliferation, but does not induce apoptosis in vitro. a Cell viability of MDA-MB-231, 4T1 and PyMT cells treated with vehicle or $20 \mu \mathrm{M}$ ZL170 for $24 \mathrm{~h}(n=3)(\mathbf{b}, \mathbf{d}$ and $\mathbf{f})$ Boyden chamber migration and invasion assays of MDA-MB-231 (b), 4 T1 (d) and PyMT ( $\mathbf{f}$ ) cells $(n=3)$. Cells pretreated with ZL170 at different doses for $24 \mathrm{~h}$ were seeded in upper insert in the presence (for invasion assay) or absence (for migration assay) of pre-coated Matrigel. $\mathbf{c}, \mathbf{e}$ and $\mathbf{g}$ Quantification of the migrated or invaded cells as shown in $\mathbf{c}$, e and $\mathbf{g}$, respectively. $\mathbf{h}$ Migration wound healing assay of MDA-MB-231 and 4 T1 cells in the presence of different doses of ZL170. $\mathbf{i}$ Quantification of the wound healing as shown in $\mathbf{h}$. $\mathbf{j}$ Cell viability of MDA-MB-231, 4T1 and PyMT cells treated with vehicle or different doses of ZL170 for $48 \mathrm{~h}(n=3)$. $\mathbf{k}$ Cell apoptosis analysis of MDA-MB-231 cells that were treated with vehicle or different doses of ZL170 for $48 \mathrm{~h}(n=3)$. Cells were co-stained with Annexin $V$ and PI. Data are represented as mean \pm S.D. ${ }^{*} P<0.05,{ }^{* *} P<0.01$, one-way ANOVA test. Scale bars, $200 \mu \mathrm{m}(\mathbf{b}, \mathbf{d}, \mathbf{f}, \mathbf{h})$

regulating cell adhesion, migration, invasion, metastasis and proliferation, extracellular matrix (ECM) remodeling, cytoskeleton remodeling, immune and inflammatory response as well as angiogenesis (Fig. 1d). Notably, ZL170-treated cells demonstrated reduced expression of ECM remodeling genes ( $M M P 1, M M P 2, M M P 9, M M P 13$, $M M P 14)$, bone metastasis-promoting genes (ADAM19, PMEPA1, THBS1, IL11), cell growth-stimulating genes (ID1 and ID3), EMT-TFs (Snail and Slug) and CSC-TFs (SOX2 and Nanog) but increased expression of tumor suppressors ( $p 15$ and $p 21)$, all of which are recognized as direct TGF $\beta$ and BMP targets $[2,7,16,17]$ and were further confirmed by reverse transcription-quantitative PCR (RT-qPCR) (Fig. 1c and e). We next assessed whether ZL170 could affect other signaling pathways that are actively involved in tumor growth, invasion and metastasis. Interestingly, we found that ZL170 had no effect on p38 MAPK, ERK, JNK, PI3K-AKT, NF-кB or Notch pathways (Additional file 1: Figure S3A), suggesting that ZL170 specifically targets TGF $\beta$ and BMP signaling pathways in TNBC cells.

\section{ZL170 inhibits kinase activities of TGF $\beta$ and BMP receptors and impairs activation of Smads in TNBC cells} Because ZL170 specifically targets the TGF $\beta$ and BMP signaling pathways, we first tested whether the compound could directly affect kinase activities of TGF $\beta$ and BMP receptors. In vitro kinase activity assay revealed that ZL170 inhibited enzymic activities of BMPR1A, BMPR1B, BMPR2 and TGFBR1 with $\mathrm{IC}_{50}$ values of $0.806,1.101,0.201$ and $1.042 \mu \mathrm{M}$, respectively (Fig. 3a). These results suggest that ZL170 is a dual inhibitor of TGF $\beta$ and BMP kinase receptors with higher activity against BMP receptors. Due to the promising selectivity profile, molecular docking was used to further illustrate the kinase activity. We compared binding models of ZL170 on TGF $\beta$ and BMP receptors. As shown, the docking results confirmed the classic binding mode of indolinones into known kinase ATP pockets (Fig. 3b; Additional file 1: Figure S3B). ZL170 was soaked into cavity of each kinase domain and lactam moiety of ZL170 could interact with His43 of BMPR1A, His282 of BMPR1B and His283 of TGFBR1, respectively, to form a conserved hydrogen. The phenolic hydroxy substituent of ZL170 occupied the gatekeeper Phe262 of TGFBR1, which contributes greatly to the strong protein occupancy. The phenolic hydroxy moiety of ZL170 developed bidentate interaction with Tyr282 of BMPR2, and a shallow hydrophobic pocket (consisting of Gly210 and Arg211) adjacent to the hinge binding area further facilitates the interaction. The lactam moiety of ZL170 is toward the hydrophobic pocket, indicating a close interaction between ZL170 and BMPR2. We next assessed the inhibitory efficacy of ZL170 on receptor kinase activity in TNBC cells where the TGF $\beta$ and BMP signaling pathways are always inappropriately upregulated $[1,10,11]$. We observed that phospho-Smad1/5 levels started to decrease at $10 \mathrm{~min}$ after treatment of MDA-MB-231 cells with $20 \mu \mathrm{M}$ ZL170 (phospho-Smad2/ 3 was undetectable in the cells) (Fig. 3c). Similarly, ZL170 decreased the levels of both phospho-Smad1/5 and phospho-Smad2/3 in PyMT cells in a time-dependent manner (Fig. 3c). ZL170 dose-dependently reduced phospho-Smad1/5 and (or) phospho-Smad2/3 levels in MDA-MB-231, 4 T1 and PyMT cells (Fig. 3d). It has been reported that exogenously-derived TGF $\beta 1$ triggers phosphorylation of both Smad2/3 and Smad1/5 (but prefers to phosphorylate Smad2/3), while BMP4 preferably phosphorylates Smad1/5 [5]. We therefore tested whether TGF $\beta$ - and BMP-stimulated Smad phosphorylation could be attenuated by ZL170. As shown, TGF $\beta 1$-stimulated Smad2/3 and Smad1/5 phosphorylation and BMP4-stimulated Smad1/5 phosphorylation were efficiently attenuated by ZL170 treatment of TNBC cells, as assessed by immunoblot and immunofluorescence analyses (Fig. 3e and f; Additional file 1: Figure S3C). In addition, ZL170 treatment of MDA-MB-231 cells efficiently reversed TGF 31 -induced Smad1 and Smad2/3 nuclear translocation and completely abolished BMP4-induced Smad1 nuclear translocation (Fig. 3g). Expression of a constitutively active TGFBR1-T204D mutant or BMPR1A-Q233D mutant in MDA-MB-231 cells substantially increased the levels of phospho-Smad2/3 and phospho-Smad1/5, which could be almost completely abolished by ZL170 treatment (Fig. 3h). Increased SBE4 (which contains four copies of Smad binding elements) transcription that was observed in TGFB1-stimulated cells or in TGFBR1-T204D stably expressing cells was efficiently reversed in the presence of 


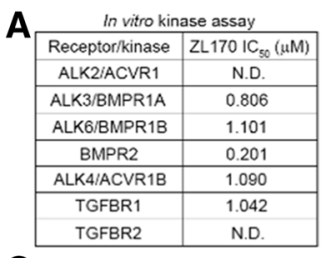

C

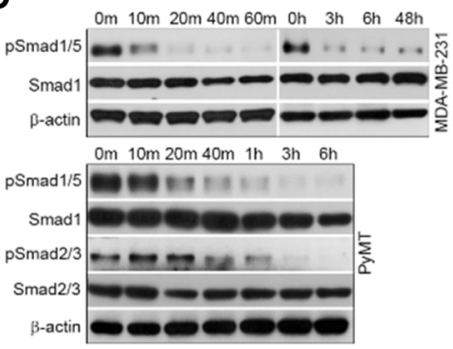

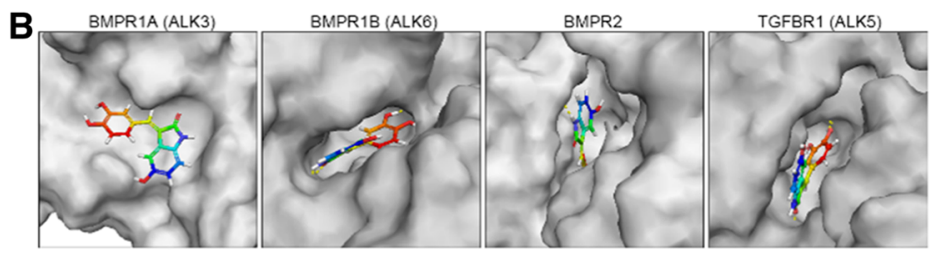

$\begin{array}{lllllllllll}\mathbf{D} \quad \mu & 0 & 5 & 10 & 20 & 0 & 5 & 10 & 20 & \mathbf{E}\end{array}$

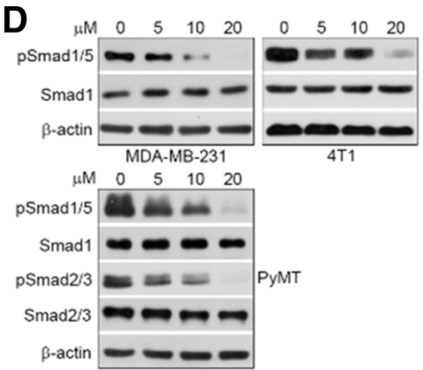

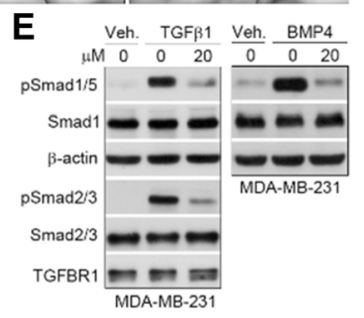

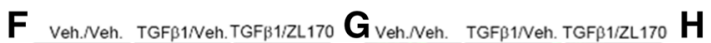

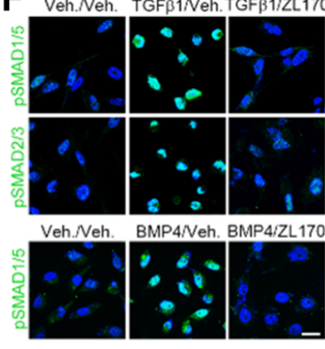

I

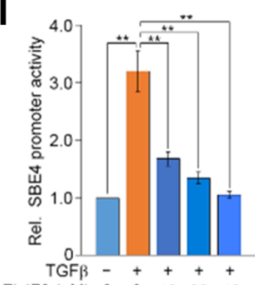

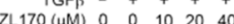

K

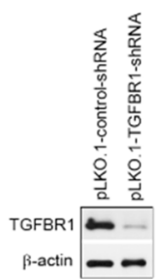

$\mathbf{L}$

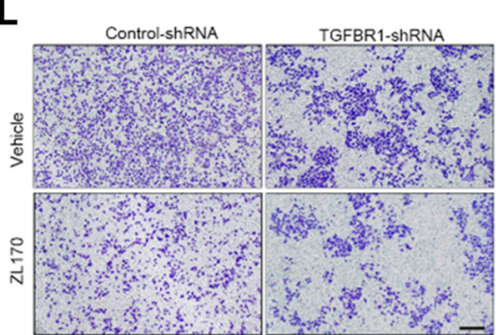

$\mathbf{N}$

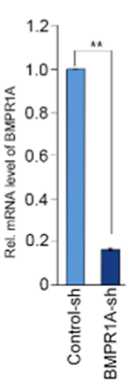

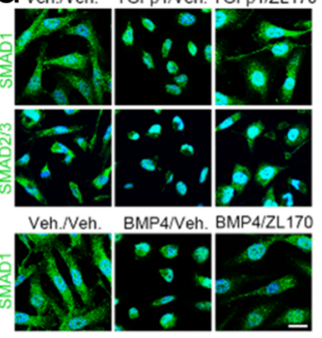

J

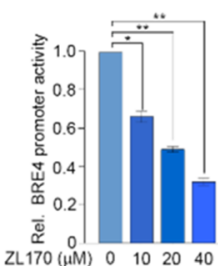

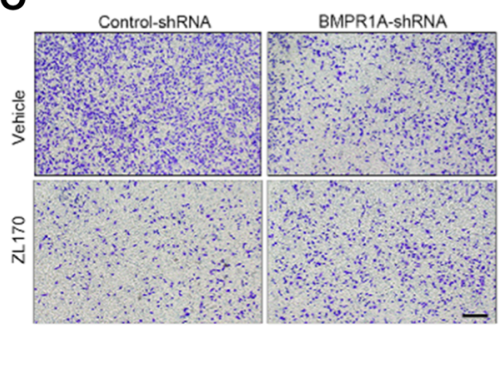

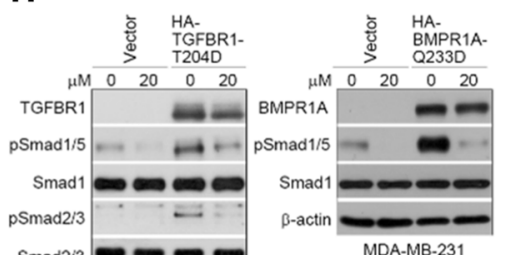

Smad $2 / 3=-m=$ MDA-MB-231
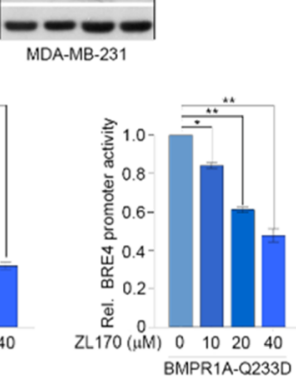

M

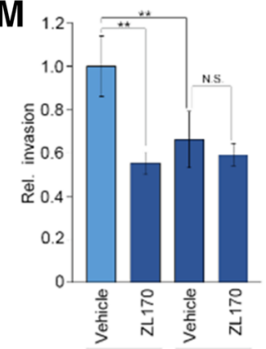

$\mathbf{P}$

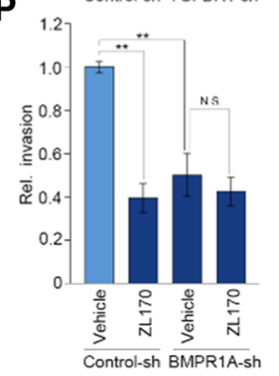

Fig. 3 (See legend on next page.) 


\begin{abstract}
(See figure on previous page.)
Fig. 3 ZL170 is a dual inhibitor of TGF $\beta$ and BMP kinase receptors and reduces activation of Smads in TNBC cells. a In vitro kinase activity assays of the inhibitory efficacy of ZL170 on phosphorylation of the substrates (BMPR1A, BMPR1B, BMPR2, TGFBR1, ACVR1B, ACVR1 and TGFBR2). b Molecular docking analysis of the potential binding between ZL170 and TGF $\beta / B M P$ receptors. Illustration of surface crystal structure of ZL170 against BMPR1A, BMPR1B, BMPR2 and TGFBR1 shown. c Representative immunoblot analyses of the levels of phospho-Smad1/5 and phospho-Smad2/3 (and their total forms) in MDA-MB-231 and PyMT cells that were treated with vehicle or ZL170 at $20 \mu \mathrm{M}$ for different times $(n=3)$. $\mathbf{d}$ Immunoblot analyses of the levels of phospho-Smad1/5 and phospho-Smad2/3 (and their total forms) in the indicated cells that were treated with vehicle or ZL170 at 5, 10 and $20 \mu \mathrm{M}$ for 3 h. $n=3$ independent experiments. e ZL170 efficiently abolished TGF $\beta 1$-stimulated and BMP4-stimulated expression of phospho-Smads in MDA-MB-231 cells as indicated by representative immunoblot analyses $(n=3)$. Cells were treated with TGF $\beta 1$ or BMP4 in combination with ZL170 at $20 \mu \mathrm{M}$ for $3 \mathrm{~h} . \mathbf{f}$ and $\boldsymbol{g}$ Representative immunofluorescent staining of phospho-Smads (f) and Smads $(\mathbf{g})$ in resting, TGF $\beta 1$-stimulated and BMP4stimulated MDA-MB-231 cells $(n=3)$. (H) ZL170 efficiently reduced the levels of phospho-Smads in TGFBR1-T204D (left panel) or BMPR1A-Q233D (right panel) stably expressing cells as indicated by representative immunoblot analyses $(n=3)$. Cells were treated with the compound for $3 \mathrm{~h}$. i SBE promoter luciferase reporter assays in MDA-MB-231 cells that were treated with TGF $\beta 1$ and increasing doses of ZL170 (left panel) or in TGFBR1-T204D stably expressing cells treated with increasing doses of ZL170 (right panel) $(n=3)$. j BRE4 promoter luciferase reporter assays in MDA-MB-231 cells treated with increasing doses of ZL170 (left panel) or in BMPR1A-Q233D stably expressing cells treated with increasing doses of ZL170 (right panel). $\mathbf{k}-\mathbf{m}$ Boyden chamber invasion assays of MDA-MB-231 cells stably expressing control-shRNA or TGFBR1-shRNA ( $\mathbf{k}$ and $\mathbf{I}$ ). Quantification of invaded cells were shown in $(M) . n=3$ independent experiments. $\mathbf{n}$ - $\mathbf{p}$ Boyden chamber invasion assays of MDA-MB-231 cells stably expressing control-shRNA or BMPR1A-shRNA ( $\mathbf{n}$ and $\mathbf{o}$ ). Quantification of invaded cells were shown in ( $\mathbf{p}) . n=3$ independent experiments. Data are represented as mean \pm S.D. ${ }^{*} P<0.05$, ** $P<0.01$, one-way ANOVA test. Scale bars $=20 \mu \mathrm{m}(\mathbf{f}, \mathbf{g})$ and $200 \mu \mathrm{m}(\mathbf{l}, \mathbf{o})$
\end{abstract}

ZL170 (Fig. 3i). ZL170 suppressed BRE4 (a BMP/SMAD transcriptional reporter) promoter activity in MDA-MB231 cells or in BMPR1A-Q233D stably expressing cells in a dose-dependent manner (Fig. 3j). To directly test whether TGFBR1 or BMPR1A is involved in the inhibition of ZL170 on cell invasion, MDA-MB-231 cells were infected with TGFBR1- or BMPR1A-shRNA and subjected to in vitro cell invasion analysis. As shown, TGFBR1-depleted cells exhibited impaired cell invasion relative to control cells, and did not respond to ZL170 treatment (Fig. 3k-p), suggesting that TGF $\beta R 1$ or BMPR1A serves as a direct target of ZL170 and is indeed involved in ZL170-mediated inhibition of cell invasion.

\section{ZL170 reduces snail and slug expression, suppresses the EMT program and impairs EMT-dependent formation of filopodium-like protrusions (FLPs) in TNBC cells}

EMT-TFs Snail and Slug have been identified as TGF $\beta$ and BMP targets $[7,17]$. RNA sequencing and RT-qPCR analyses showed that mRNA levels of Snail and Slug were substantially reduced in ZL170-treated TNBC cells in which the TGF $\beta$ and BMP pathways were robustly impaired (Fig. 1c and e; Additional file 1: Figure S4A). Immunoblot analysis further revealed that protein levels of Snail and Slug started to decrease at $3 \mathrm{~h}$ after treatment of MDA-MB-231 and PyMT cells with $20 \mu \mathrm{M}$ ZL170 (Fig. 4a). ZL170 dose-dependently decreased Snail and Slug protein levels in three TNBC cell lines (Fig. 4b). Interestingly, ZL170 treatment $(20 \mu \mathrm{M}, 3 \mathrm{~h})$ efficiently reduced Snail and Slug protein levels, while treatment of LY2157299 $(20 \mu \mathrm{M}, 3 \mathrm{~h})$, a TGF $\beta$-specific inhibitor which is currently in phase I/II clinical trials, did not alter Snail or Slug protein expression in MDA-MB-231 and PyMT cells (Fig. 4c), suggesting that ZL170 has a stronger inhibitory effect on Snail and Slug expression than LY2157299. As expected, TGF $\beta 1$ and
BMP4 potently stimulated Snail and Slug expression at both mRNA and protein levels, which was completely abolished by ZL170 (Fig. 4d-g; Additional file 1: Figure S4B and C). Expression of a constitutively active TGFBR1T204D mutant in MDA-MB-231 cells markedly increased Snail and Slug expression levels, which was efficiently reversed in the presence of ZL170 (Fig. 4h and i). ZL170 treatment of TNBC cells increased epithelial features but reduced mesenchymal features, as evidenced by the increased levels of epithelial markers such as E-cadherin and Keratin 18 but decreased expression of mesenchymal markers such as fibronectin, $\mathrm{N}$-cadherin and vimentin (Fig. 4j-m; Additional file 1: Figure S4D-F). Furthermore, TGF $\beta 1$ and BMP4 significantly decreased E-cadherin expression in PyMT cells, and the decreased E-cadherin was efficiently restored in the presence of ZL170 (Fig. 4n). It has been reported that EMT-dependent induction of tumor-initiating and metastasis-forming potentials involves and depends on the enhancement of assembled filopodium-like protrusions (FLPs), cytoskeletal actin-rich protrusions morphologically resembling filopodia formed by aggressive cancer cells [18]. These observations, together with our present demonstration that ZL170 efficiently suppressed EMT program in TNBC cells, promoted us to ask whether ZL170 could affect FLP formation in MDA-MB-231 cells. Colocalization of F-actin with the actin-bundling protein cortactin [19] was used to identify FLPs. As shown, FLPs can be readily detected on the surface of control cells, while FLPs were almost completely absent in ZL170-treated cells (Fig. 4o). Together, these findings suggest that ZL170 treatment of TNBC cells reduces EMT-TF expression, suppresses the EMT program and impairs EMT-dependent FLP formation, thereby hindering TNBC cell growth, invasion and metastasis. 


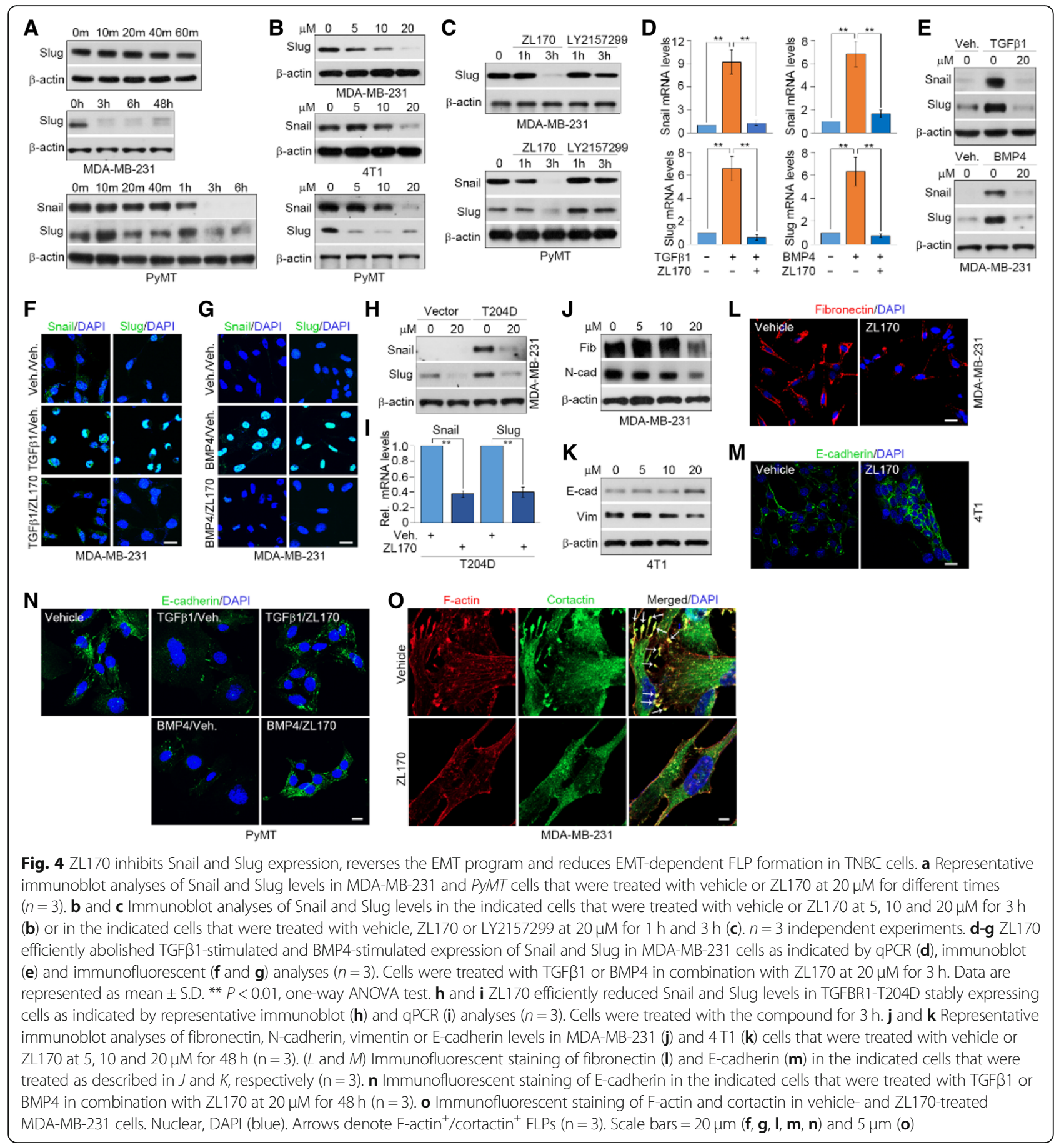

\section{ZL170 suppresses stemness function in TNBC cells}

TGF $\beta$ and BMP signaling pathways promote expression of EMT-TFs and cancer stem cell (CSC)-associated TFs (CSC-TFs) to induce EMT and increase stemness function in aggressive cancer cells, thereby facilitating tumor invasion and metastasis [1, 17]. Accordingly, we evaluated whether ZL170 could affect stemness function in TNBC cells. We found that ZL170 treatment of MDA-MB-231 cells markedly reduced Nanog and Sox2 expression at both mRNA and protein levels but did not affect Oct4 or Bmi1 expression (Fig. 1e; Fig. 5a and b). ZL170 also decreased levels of CD49f and CD44, two markers of the CSC population [20-22], as assessed by flow cytometry analysis (Fig. $5 \mathrm{c}$ and d). In addition, aldehyde dehydrogenase 1 (ALDH1) has been identified as a CSC marker and a predictor of poor clinical outcome $[15,23]$. We observed that ZL170 remarkably reduced the percentage of $\mathrm{ALDH}^{+} \mathrm{CSC}$ subpopulation (Fig. 5e 


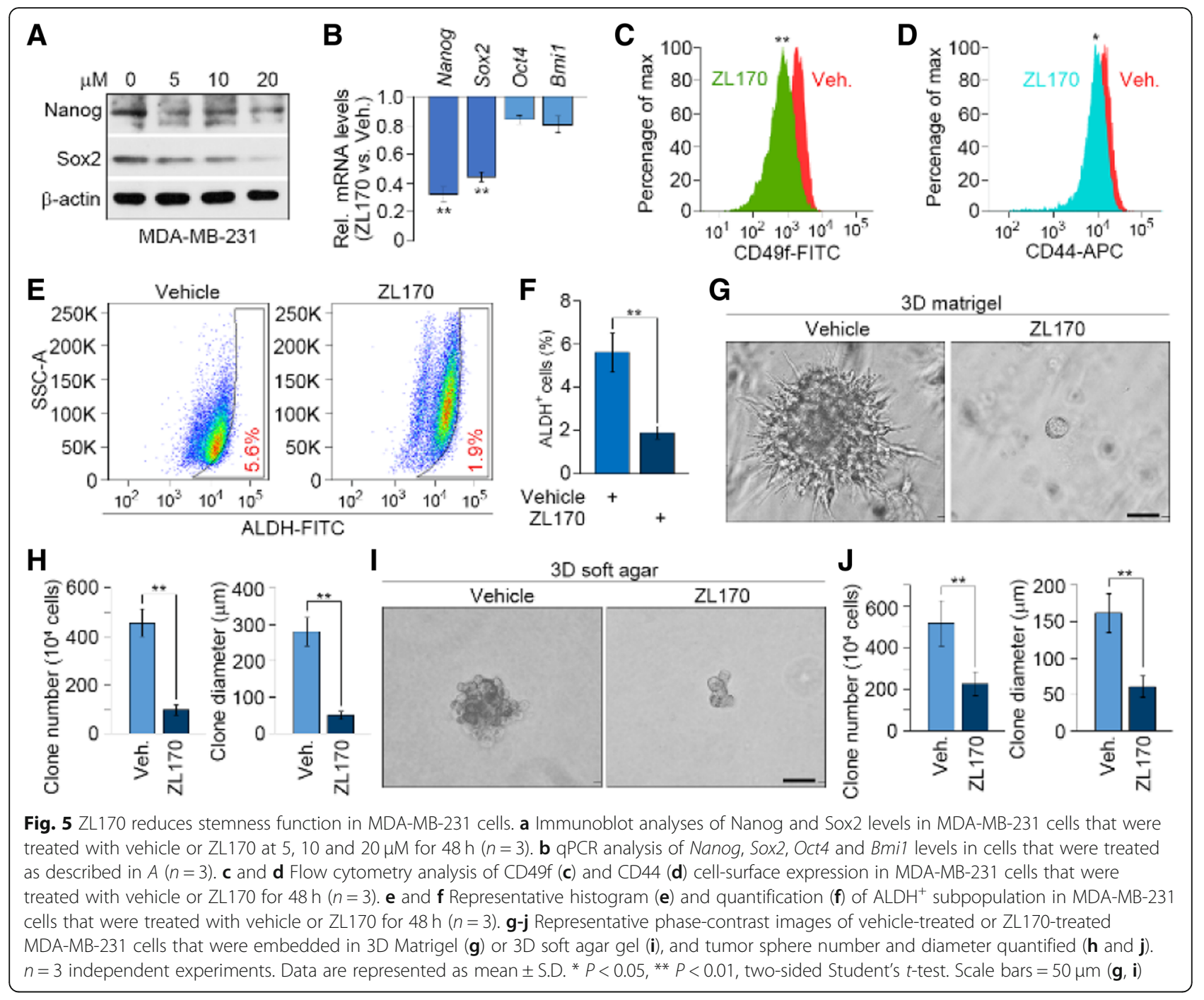

and f). Furthermore, ZL170 remarkably reduced tumorsphere- or colony-forming potential (that is, stemness) of MDA-MB-231 cells cultured in 3-dimentional (3D) Matrigel or 3D soft agar as evidenced by fewer, smaller and less invasive tumor spheres (or colonies) formed from ZL170-treated single cells (Fig. 5g-j).

\section{ZL170 impairs TNBC osteolytic bone metastasis and xenograft tumor growth by targeting the TGF $\beta$-Smads and BMP-Smads signaling pathways}

The TGF $\beta$ and BMP signaling pathways are aberrantly upregulated in bone metastases samples from breast cancer patients [24]. Preclinical models have confirmed that the TGF $\beta$ and BMP signaling pathways induces the osteolytic phenotype and consequently promotes the progression of osteolytic bone metastases [3, 25]. We therefore tested the antitumor efficacy of ZL170 using a mouse model of bone metastasis. For this purpose, luciferase-labelled SCP2 cells, a highly bone metastatic
MDA-MB-231 subline, were intracardially injected into the circulation of nude mice followed by bioluminescent imaging (BLI) of bone metastasis at 5 weeks post-inoculation. BLI analysis demonstrated that ZL170 $(80 \mathrm{mg} / \mathrm{kg} /$ day) markedly decreased tumor bone burden 2 weeks after injection when compared to vehicle-treated mice (Fig. 6a and b). ZL170-treated mice demonstrated significantly reduced osteolytic bone lesions relative to vehicle-treated mice, as assessed by micro-computed tomography $(\mu-\mathrm{CT})$ and H.E. staining (Fig. 6c-e). Consistent with these results, histological analysis revealed a remarkable decrease in the numbers of tartrate-resistant acid phosphatase-positive $\left(\right.$ TRAP $\left.^{+}\right)$osteoclasts in both tibia and femur of ZL170-treated mice as compared to vehicle-treated mice (Fig. 6f and g). Overall, these data demonstrated that ZL170 significantly decreased osteolytic bone metastases of MDA-MB-231 cells. Because ZL170 significantly reduced TNBC cell growth in vitro (Fig. 2j), we next asked whether the compound could affect TNBC cell growth in 


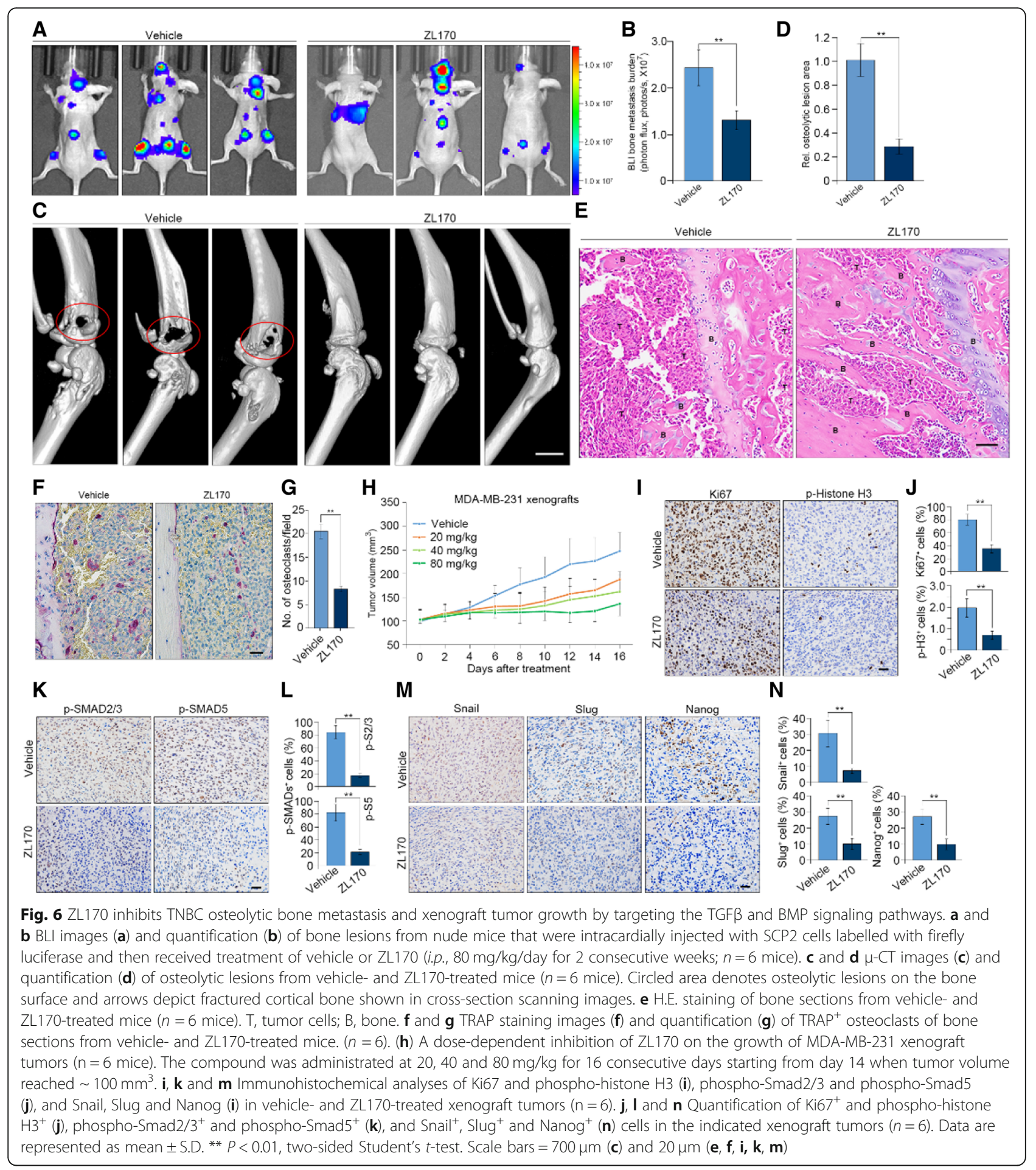

vivo. Accordingly, cells were subcutaneously injected into the nude mice and ZL170 was administrated (20, 40 and $80 \mathrm{mg} / \mathrm{kg} /$ day, respectively) starting on day 14 when the xenograft tumors grew to around $100 \mathrm{~mm}^{3}$. After 16 days of treatment, ZL170 efficiently inhibited xenograft tumor growth in a dose-dependent manner without eliciting toxicity on tumor-bearing mice (Fig. 6h;
Additional file 1: Figure S5A). Consistently, a marked reduction in numbers of proliferative $\left(\mathrm{Ki} 67^{+}\right)$and mitotic (phospho-Histone $\mathrm{H3}^{+}, \mathrm{pH}^{+}$) cells was observed in ZL170-treated tumors, whereas numbers of apoptotic (cleaved caspase $3^{+}$) cells were comparable between ZL170- and vehicle-treated tumors (Fig. 6i and j; Additional file 1: Figure S5B and C), confirming the in vitro 
results that ZL170 did not induce obvious apoptosis in cultured cells. As expected, phospho-Smad2/3 and phospho-Smad5 were substantially decreased in ZL170-treated tumors as compared to vehicle-treated tumors (Fig. 6k and l). The levels of Snail, Slug and Nanog were markedly reduced in the xenograft tumors following ZL170 treatment (Fig. $6 \mathrm{~m}$ and n). Taken together, these results demonstrated that ZL170 efficiently reduced TNBC osteolytic bone metastasis and xenograft tumor growth by targeting TGF $\beta$-Smad and BMP-Smad signaling pathways.

\section{ZL170 reduces primary tumor growth and lung metastases in PyMT transgenic mice}

We next tested whether the TGF $\beta / B M P$ dual inhibitor ZL170 could affect the progression, invasion and metastasis of spontaneous breast tumors using a MMTV-PyMT transgenic mouse model of metastatic breast cancer that mirrors the multi-step progression of human breast cancers [26]. For this purpose, 2-month-old female mice that have developed multiple spontaneous breast tumors in similar size $\left(\sim 0.4 \mathrm{~cm}^{3} /\right.$ mouse $)$ were administrated with vehicle or ZL170 (40 mg/kg/day) for consecutive 4 weeks. We observed that ZL170 significantly reduced the growth of primary breast tumors without eliciting toxicity on tumor-bearing mice (Fig. 7a; Additional file 1: Figure S6A). ZL170-treated mice exhibited markedly fewer and smaller metastatic lung nodules relative to vehicle-treated mice (Fig. $7 \mathrm{~b}$ and c). Histological analysis revealed that ZL170 remarkably decreased numbers of $\mathrm{Ki}^{+} 7^{+}$and $\mathrm{pH}^{+}$cells, without increasing numbers of apoptotic cells (Fig. 7d and e; Additional file 1: Figure S6B and C). In consistent with the observations in vitro, phosphoSmad2/3 and phospho-Smad5 were markedly decreased in ZL170-treated tumors where the levels of Snail, Slug and Nanog were robustly decreased as well (Fig. 7f-i). Notably, we observed that the levels of E-cadherin were markedly increased but vimentin expression was significantly reduced in ZL170-treated tumors, suggesting that ZL170 reverses the EMT program in the in vivo set (Fig. $7 j$ and k). Cytokeratin-14 (K14) has recently been recognized as a marker for highly migratory cancer cells in breast tumors that can initiate collective invasion, a critical step during metastatic progression of breast tumors [15, 27]. We observed that $\mathrm{K}_{14}{ }^{+}$cells were enriched at the invasive border in vehicle-treated tumors, forming strands invading into the surrounding stromal tissues (top panel, Fig. 7l). In striking contrast, ZL170-treated tumors failed to exhibit a locally invasive phenotype and the K14-enriched invasive strands were undetectable in the stromal tissue (bottom panel, Fig. 7l). The TGF $\beta$ and BMP signaling pathways have been reported to determine microenvironmental modification that heavily influences tumor progression, invasion and metastasis $[1,3]$. We therefore sought to test whether ZL170 could induce microenvironmental change in primary breast tumors. As shown, ZL170-treated tumors exhibited reduced ECM deposition and impaired infiltration of $\mathrm{CD}_{31}{ }^{+}$endothelial cells, $\alpha-\mathrm{SMA}^{+}$cancer-associated fibroblasts as well as $\mathrm{F} 4 / 80^{+}$macrophages (Fig. $7 \mathrm{~m}$ and $\mathrm{n}$ ), suggesting that ZL170 treatment created a suppressive tumor microenvironment, which in turn suppressed tumor growth, invasion and metastasis in TNBC.

\section{Discussion}

The TGF $\beta$ and BMP signaling pathways are aberrantly upregulated in various types of advanced metastatic cancers and play essential roles in controlling cancer stemness, EMT, metastasis and chemoresistance. Targeting the TGF $\beta$ and BMP signaling pathways is therefore an attractive anti-cancer therapeutic approach. Many small-molecule inhibitors that solely target TGF $\beta$ or BMP kinase receptors have been investigated for metastatic cancers in preclinical studies, and two of them are currently investigated in clinical trials [1, 12, 13, 28-30]. It should be noted that TGF $\beta$ and BMP signaling pathways are both actively involved in many cellular processes during tumor malignant progression. Targeting each pathway by the current TGF $\beta$-specific or BMP-specific inhibitors is insufficient to block activation of Smads as well as Smad-mediated transcription of downstream targets. In support of this notion, we observe that ZL170 treatment of TNBC cell lines for $3 \mathrm{~h}$ almost completely abolishes expression of Snail and Slug, while treatment of LY2157299, a TGF $\beta$-specific inhibitor does not affect Snail or Slug expression. Snail and Slug have been widely recognized as important drivers of tumor invasion and metastasis by inducing the EMT program in malignant tumor cells [31-34]. We therefore propose that the TGF $\beta / B M P$ dual inhibitor ZL170 has a stronger efficacy against TNBC growth, invasion and metastasis than the TGF $\beta$-specific inhibitor LY2157299. Importantly, simultaneous inhibition of TGF $\beta$ and BMP signaling pathways by treatment with ZL170 might overcome chemoresistance that is frequently observed in TGF $\beta$-specific or BMP-specific inhibitor-treated cells. However, further work is required to address this issue.

Cancer stem cells (CSCs), a minority population of the solid malignancies that possess the defining features of clonogenicity and self-renewal, are reported to be associated with tumor metastasis, recurrence and chemoresistance $[15,20,35]$. The EMT program is known to generate cancer cells with properties of stem cells characterized by increased expression of stem cell markers, augmented chemoresistance to therapy and enhanced tumor-initiating activity (that is, stemness) in vitro and in vivo [20]. CSC-TFs (e.g. Nanog and Sox2) as well as 


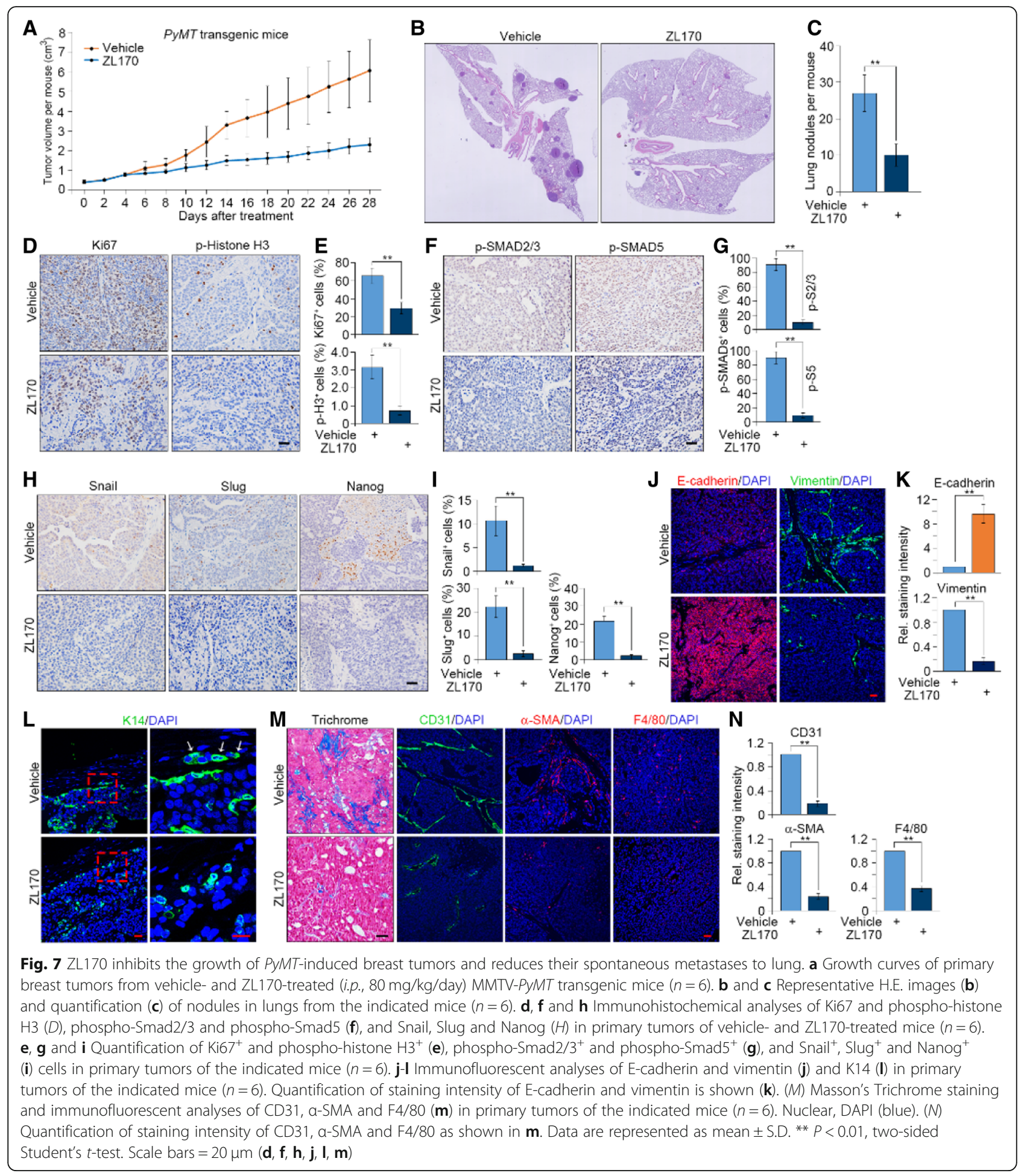

EMT-TFs (e.g. Snail and Slug) have been identified as target genes of TGF $\beta$ and BMP signaling pathways $[1,17]$, and most importantly, their expression levels are reduced in ZL170-treated MDA-MB-231 cultures and xenograft tumors as well as PyMT primary tumors, in which the EMT program is strongly suppressed as evidenced by acquisition of E-cadherin and loss of vimentin. We propose that ZL170 impairs the stemness of TNBC cells in vitro and in vivo not only by directly targeting CSC-TFs Nanog and Sox2 but also by targeting EMT-TFs Snail and Slug to inhibit EMT-conferred CSC characteristics, and thus reduces CSC-associated 
tumor metastasis, recurrence and chemoresistance in TNBC.

The activated TGF $\beta$ and BMP signaling pathways in epithelial and stromal compartments are both recognized to have a substantial role in regulating tumor growth, invasion and metastasis [3, 36-39]. In the present study, we find that disruption of epithelial TGF $\beta$ and BMP pathways by ZL170 may create a suppressive stromal microenvironment characterized by decreased ECM deposition as well as impaired recruitment and proliferation of cancer-associated fibroblasts (CAFs), endothelial cells and immune cells, which in turn reduces epithelial tumor growth, invasion and metastasis. On the other hand, targeting stromal TGF $\beta$ and BMP pathways by ZL170 may directly impair the recruitment, activation and function of CAFs and immune cells, which in turn reduces epithelial tumor growth, invasion and metastasis as well.

\section{Conclusions}

The data presented here suggest that ZL170 potently inhibits tumor growth, invasion and metastasis by simultaneously targeting TGF $\beta$ and BMP signaling pathways in both epithelial and stromal compartments of TNBC tumors. The compound can be further developed as a potent anti-metastatic agent used in combination with cytotoxic drugs for treatment of TNBC as well as other advanced metastatic cancers.

\section{Additional file}

Additional file 1: Figure S1. Extraction, total synthesis and characterization of ZL170. Figure S2. ZL170 treatment does not induce C57BL6 mice death or any obvious adverse health effects. Figure S3. ZL170 is a potent dual inhibitor of TGF $\beta$ and BMP kinase receptors. Figure S4. ZL170 reverses the EMT program in TNBC cells. Figure S5. Administration of ZL170 does not induce apoptosis or elicit toxicity on key organs of tumor-bearing mice. Figure S6. ZL170 treatment does not induce apoptosis or elicit toxicity on key organs of PyMT transgenic mice. (DOCX $6822 \mathrm{~kb})$

\section{Abbreviations}

ALDH: Aldehyde dehydrogenase; ATP: Adenosine triphosphate; BFI: Biofluorescent imaging; BMP: Bone morphogenetic protein; BMPR1A: Bone morphogenetic protein receptor type 1A; BMPR1B: Bone morphogenetic protein receptor type 1B; BMPR2: Bone morphogenetic protein receptor type-2; CAF: Cancer-associated fibroblast; CSC: Cancer stem cell; ECM: Extracellular matrix; EMT: Epithelial-mesenchymal transition; EtOAc: Ethyl acetate; EtOH: Ethyl alcohol; FLP: Filopodium-like protrusion; TF: Transfer factor; TGFBR1: Transforming growth factor-beta receptor type-1; TGFB: Transforming growth factor-beta; TNBC: Triple-negative breast cancer; TRAP: Tartrate-resistant acid phosphatase; a-SMA: a-smooth muscle actin; $\mu$ $C T$ : Micro-computed tomography

\section{Acknowledgements}

Not applicable.

\section{Funding}

This research was supported by the Startup Fund from China Pharmaceutical University, the funds from National Natural Science Foundation of China
(81572745, 91539115 and 81603134), the National Natural Science Fund for Distinguished Young Scholars (81525026), the Jiangsu Provincial Natural Science Fund for Distinguished Young Scholars (BK20170029), the Jiangsu Provincial Natural Science Fund for Young Scholars (BK20160758), the Jiangsu Provincial Innovative Research Program, the Shenzhen Government's Plan of Science and Technology (JCYJ20170412110504956), the fund from State Key Laboratory of Natural Medicines of China Pharmaceutical University (SKLNMZZCX201808), the fund from National Natural Science Foundation of China (81773606), "Double First-Class" University project (CPU2018GF02) and the fund from Collaborative Innovation Center for Gannan Oil-Tea Camellia Industrial Development (YP201608).

\section{Availability of data and materials}

All data generated or analysed during the present study are included in this published article.

\section{Authors' contributions}

Z-QW and Y-XC supervised the project, designed experiments, analyzed data and wrote the manuscript. LD, L-JL, RF, YL and $Y X$ performed experiments. Y-MY extracted and characterized ZL170. All authors read and approved the final manuscript.

\section{Ethics approval and consent to participate}

The experimental protocol was approved by the Animal Welfare and Ethics Committee of China Pharmaceutical University.

Consent for publication

Not applicable.

\section{Competing interests}

The authors declare that they have no competing interests.

\section{Publisher's Note}

Springer Nature remains neutral with regard to jurisdictional claims in published maps and institutional affiliations.

Received: 20 December 2018 Accepted: 6 March 2019

Published online: 21 March 2019

References

1. Akhurst RJ, Hata A. Targeting the TGF-beta signalling pathway in disease. Nat Rev Drug Discov. 2012;11:790-811.

2. Massague J. TGF-beta signalling in context. Nat Rev Mol Cell Biol. 2012;13: 616-30.

3. Pickup M, Novitskiy S, Moses HL. The roles of TGF-beta in the tumour microenvironment. Nat Rev Cancer. 2013;13:788-99.

4. Schmierer B, Hill CS. TGF-beta-SMAD signal transduction: molecular specificity and functional flexibility. Nat Rev Mol Cell Biol. 2007;8:970-82.

5. Liu IM, Schilling SH, Knouse KA, Choy L, Derynck R, Wang XF. TGF-betastimulated Smad1/5 phosphorylation requires the ALK5 L45 loop and mediates the pro-migratory TGF-beta switch. EMBO J. 2009;28:88-98.

6. Moses HL, Roberts AB, Derynck R. The discovery and early days of TGF-beta: a historical perspective, vol. 8; 2016. pii: a021865

7. Massaque J. TGF-beta in Cancer. Cell. 2008;134:215-30.

8. Dent R, Trudeau M, Pritchard Kl, Hanna WM, Kahn HK, Sawka CA, et al. Triple-negative breast cancer: clinical features and patterns of recurrence. Clin Cancer Res. 2007;13:4429-34.

9. Kennecke $H$, Yerushalmi $R$, Woods $R$, Cheang MC, Voduc D, Speers $\mathrm{CH}$, et al. Metastatic behavior of breast cancer subtypes. J Clin Oncol. 2010;28:3271-7.

10. Ivanović $V$, Todorović-Raković $N$, Demajo M, Nešković-Konstantinović Z, Subota V, Ivanišević-Milovanović $O$, et al. Elevated plasma levels of transforming growth factor- $\beta 1$ (TGF- $\beta 1$ ) in patients with advanced breast cancer: association with disease progression. Eur J Cancer. 2003;39:454-61.

11. Muraoka-Cook RS, Shin I, Yi JY, Easterly E, Barcellos-Hoff MH, Yingling JM, et al. Activated type I TGF-beta receptor kinase enhances the survival of mammary epithelial cells and accelerates tumor progression. Oncogene. 2006;25:3408-23.

12. Nagaraj NS, Datta PK. Targeting the transforming growth factor-beta signaling pathway in human cancer. Expert Opin Investig Drugs. 2010;19: 77-91. 
13. Owens P, Pickup MW, Novitskiy SV, Giltnane JM, Gorska AE, Hopkins CR, et al. Inhibition of BMP signaling suppresses metastasis in mammary cancer. Oncogene. 2015;34:2437-49.

14. Newman DJ, Cragg GM, Snader KM. Natural products as sources of new drugs over the period 1981-2002. J Nat Prod. 2003;66:1022-37.

15. Ni T, Li XY, Lu N, An T, Liu ZP, Fu R, et al. Snail1-dependent p53 repression regulates expansion and activity of tumour-initiating cells in breast cancer. Nat Cell Biol. 2016;18:1221-32.

16. Fournier PG, Juarez $P$, Jiang G, Clines GA, Niewolna M, Kim HS, et al. The TGF-beta signaling regulator PMEPA1 suppresses prostate cancer metastases to bone. Cancer Cell. 2015;27:809-21.

17. Yeh HW, Hsu EC, Lee SS, Lang YD, Lin YC, Chang CY, et al. PSPC1 mediates TGF-beta1 autocrine signalling and Smad2/3 target switching to promote EMT, stemness and metastasis. Nat Cell Biol. 2018;20:479-91.

18. Shibue T, Brooks MW, Weinberg RA. An integrin-linked machinery of cytoskeletal regulation that enables experimental tumor initiation and metastatic colonization. Cancer Cell. 2013:24:481-98.

19. Bowden ET, Onikoyi E, Slack R, Myoui A, Yoneda T, Yamada KM, et al. Colocalization of cortactin and phosphotyrosine identifies active invadopodia in human breast cancer cells. Exp Cell Res. 2006;312:1240-53.

20. Mani SA, Guo W, Liao MJ, Eaton EN, Ayyanan A, Zhou AY, et al. The epithelial-mesenchymal transition generates cells with properties of stem cells. Cell. 2008;133:704-15.

21. Chou J, Lin JH, Brenot A, Kim JW, Provot S, Werb Z. GATA3 suppresses metastasis and modulates the tumour microenvironment by regulating microRNA-29b expression. Nat Cell Biol. 2013;15:201-13.

22. Ye X, Tam WL, Shibue T, Kaygusuz Y, Reinhardt F, Ng Eaton E, et al. Distinct EMT programs control normal mammary stem cells and tumour-initiating cells. Nature. 2015:525:256-60.

23. Ginestier C, Hur MH, Charafe-Jauffret E, Monville F, Dutcher J, Brown M, et al. ALDH1 is a marker of normal and malignant human mammary stem cells and a predictor of poor clinical outcome. Cell Stem Cell. 2007;1:555-67.

24. Kang Y, He W, Tulley S, Gupta GP, Serganova I, Chen CR, et al. Breast cancer bone metastasis mediated by the Smad tumor suppressor pathway. Proc Natl Acad Sci U S A. 2005;102:13909-14

25. Korpal M, Yan J, Lu X, Xu S, Lerit DA, Kang Y. Imaging transforming growth factor-beta signaling dynamics and therapeutic response in breast cancer bone metastasis. Nat Med. 2009;15:960-6.

26. Lin EY, Jones JG, Li P, Zhu L, Whitney KD, Muller WJ, et al. Progression to malignancy in the polyoma middle $T$ oncoprotein mouse breast cancer model provides a reliable model for human diseases. Am J Pathol. 2003;163: 2113-26.

27. Cheung KJ, Gabrielson E, Werb Z, Ewald AJ. Collective invasion in breast cancer requires a conserved basal epithelial program. Cell. 2013;155:1639-51.

28. Lee YC, Cheng CJ, Bilen MA, Lu JF, Satcher RL, Yu-Lee LY, et al. BMP4 promotes prostate tumor growth in bone through osteogenesis. Cancer Res. 2011;71:5194-203.

29. Hao J, Ho JN, Lewis JA, Karim KA, Daniels RN, Gentry PR, et al. In vivo structure-activity relationship study of dorsomorphin analogues identifies selective VEGF and BMP inhibitors. ACS Chem Biol. 2010;5:245-53.

30. Hao J, Lee R, Chang A, Fan J, Labib C, Parsa C, et al. DMH1, a small molecule inhibitor of BMP type i receptors, suppresses growth and invasion of lung cancer. PLoS One. 2014;9:e90748.

31. Thiery JP, Acloque H, Huang RY, Nieto MA. Epithelial-mesenchymal transitions in development and disease. Cell. 2009:139:871-90.

32. Nieto MA. Epithelial plasticity: a common theme in embryonic and cancer cells. Science. 2013:342:1234850.

33. Peinado H, Olmeda D, Cano A. Snail, Zeb and bHLH factors in tumour progression: an alliance against the epithelial phenotype? Nat Rev Cancer. 2007;7:415-28

34. De Craene B, Berx G. Regulatory networks defining EMT during cancer initiation and progression. Nat Rev Cancer. 2013;13:97-110.

35. Singh A, Settleman J. EMT, cancer stem cells and drug resistance: an emerging axis of evil in the war on cancer. Oncogene. 2010;29:4741-51.

36. Hanahan D, Coussens LM. Accessories to the crime: functions of cells recruited to the tumor microenvironment. Cancer Cell. 2012;21:309-22.

37. Jung Y, Kim JK, Shiozawa Y, Wang J, Mishra A, Joseph J, et al. Recruitment of mesenchymal stem cells into prostate tumours promotes metastasis. Nat Commun. 2013:4:1795
38. Quante M, Tu SP, Tomita H, Gonda T, Wang SS, Takashi S, et al. Bone marrow-derived myofibroblasts contribute to the mesenchymal stem cell niche and promote tumor growth. Cancer Cell. 2011;19:257-72.

39. Navab R, Strumpf D, Bandarchi B, Zhu CQ, Pintilie M, Ramnarine VR, et al. Prognostic gene-expression signature of carcinoma-associated fibroblasts in non-small cell lung cancer. Proc Natl Acad Sci U S A. 2011;108:7160-5.

\section{Ready to submit your research? Choose BMC and benefit from:}

- fast, convenient online submission

- thorough peer review by experienced researchers in your field

- rapid publication on acceptance

- support for research data, including large and complex data types

- gold Open Access which fosters wider collaboration and increased citations

- maximum visibility for your research: over $100 \mathrm{M}$ website views per year

At BMC, research is always in progress.

Learn more biomedcentral.com/submissions 